\title{
ARCHITECTURE, ART ET INDUSTRIE
}

\author{
INSTITUTIONS ET ENSEIGNEMENT EN HONGRIE \\ À L'ÉPOQUE DU DUALISME ${ }^{1}$
}

\begin{abstract}
Architecture, art and industry - institutions and education in Hungary in the age of dualism. After the AustroHungarian compromise of 1867, Hungary launched a programme of modernisation and nation building, which included the improvement of education in the areas of architecture and the applied arts. The government made efforts to achieve this by radically transforming the institutional framework, reforming existing establishments, and setting up new ones. In 1871 the Joseph Polytechnic, which had been in operation since 1856, was accorded the status of a university (Joseph Technical University). In 1872 the School of Drawing was launched. Within it the School of Applied Arts was established in 1880, the institution becoming independent in 1896. In 1888 the Municipal School of Industrial Drawing of Budapest, the successor of earlier lower level schools of drawing, was established, now as a new centre for the training of artisans. The State High School of Industry opened its school at the end of 1879. Teachers and students had access to an increasing number of French, German, English and Hungarian books and pattern sheets acquired systematically by the institutions, which also used plaster casts and models as teaching aids. Some newly-founded schools operated in conjunction with museums of their respective disciplines.

Keywords: education, architecture, applied arts, Hungary, Joseph Technical University, School of Drawing, Municipal School of Industrial Drawing of Budapest, State High School of Industry, pattern sheets, plaster models, museum
\end{abstract}

A la suite du compromis de 1867 - dans le cadre de la Monarchie Austro-hongroise - la Hongrie devient un pays indépendant dans ses affaires intérieures. L'élan de la construction de la nation couvre la culture et ses institutions, ci-inclus la sphère de l'architecture, de l'art et de l'industrie. Pour atteindre ce but, on réforme les établissements d'enseignement existant, ou on en instaure de nouveaux. Il faut créer les conditions personnelles adéquates et les méthodes professionnelles de la formation, les outils nécessaires doivent être acquis ou inventés. C'est de cette façon qu'on pourra amener le pays dans la voie de la modernisation pour, enfin, ratrapper l'Europe de l'Ouest dans les domaines en question.

\footnotetext{
* József Sisa, scientific advisor, Institute of Art History, Research Centre for the Humanities, Hungarian Academy of Sciences, email: sisa.jozsef@btk.mta.hu
}

La formation élémentaire des maîtres-bâtisseurs et des maîtres des autres métiers se déroulaient traditionnellement au sein des corporations. ${ }^{2}$ Pour approfondir leur connaissance, l'enseignement du dessin était obligatoire pour les apprentis. A la fin du XVIII ${ }^{e}$ siècle, on instaura des écoles de dessin dans plusieurs endroits du pays, souvent avec des instituteurs très instruits. ${ }^{3}$ Bien que la rigueur ait beaucoup diminué dans la dernière phase de son existence, le système des guildes, essentiellement féodal, n'a été supprimé qu'en 1872 en Hongrie. Les institutions modernes d'enseignement se sont formées peu à peu, parallèlement à l'ancien système.

La formation supérieure des architectes en Hongrie remonte à l'Institutum Geometricum, fondé en 1782 au sein de l'université de Pest. ${ }^{4}$ Bien que ce dernier ait joué un róle éminent dans la formation des ingénieurs, dans le programme d'études, l'architecture elle demeurait moins importante. En 1846, l'École industrielle Joseph (József Ipartanoda) fut instaurée 
et bientốt l'Institutum Geometricum y fut attaché. (Dans le nom de l'école, „Joseph" se réfère à l'archiduc Joseph, le palatin actuel de Hongrie, qui appuyait de tout son pouvoir la modernisation du pays.) En 1856, l'institution, établie à Buda, fut renommée Polytechnique royal Joseph (Királyi József Politechnikum), laissant présager de bonnes perspectives. Antal Szkalnitzky fut nommé, comme premier architecte-professeur éminent, instituteur de „l'architecture artistique et ornamentale" (fig. 1). Il avait essentiellement en charge l'enseignement des styles historiques. Malheureusement, sa maladie puis sa mort précoce ont interrompu sa brillante carrière.

En 1871, le ministre de la culture, le baron József Eötvös accorda à polytechnique le nom et le rang d'université, lui confiant des ambitions très élevées. Désormais, elle sera officiellement nommée Université royale Joseph de technologie (Királyi József Múegyetem), plus brièvement Université de technologie (fig. 2). L'obtention de ce titre entraina des changements favorables, ci-inclus que l'architecture devint une faculté indépendante. L'édification d'un nouveau centre pour l'institution sur le boulevard du Musée signifiait l'amélioration de son infrastructure.

Bien que les ambitions aient été grandes, l'établissement d'un enseignement de haut niveau à un grand nombre s'avera être un processus long. Même au milieu des années 1880 c'est avec un brin d'amertume qu'on faisait remarquer: „C'est une coutume généralement acceptée, un véritable dogme que quiconque voulant devenir architecte se devait de fréquenter une institution étrangère pour plusieurs années." ${ }^{5}$ Cela ne devint naturel qu'à partir de la fin du siècle qu'un jeune homme hongrois fasse ses études d'architecture entièrement à Budapest.

Après le départ précoce d'Antal Szkalnitzky, deux personages importants, Imre Steindl (fig. 3) et Alajos Hauszmann (fig. 4) laissèrent leur empreinte à l'Université de technologie pendant les décennies suivantes. Le premier avait fait ses études à Vienne, le second à Berlin - ce n'est pas un hasard, ces deux villes exerçaient la plus grande influence en ce temps-là sur l'architecture hongroise. Hormis l'enseignement, tous les deux travaillent aux projets de nombreux édifices importants, Steindl p.e. le parlement (et aussi le bâtiment de l'Université de technologie), Hauszmann le palais royal. Ils se partagèrent les cours à l'Université de technologie essentiellement selon les époques historiques, Steindl enseignant la morphologie de l'architecture médiévale, Hauszmann celle de l'architecture antique-classique. Au début de l'activité de l'Université de technologie,

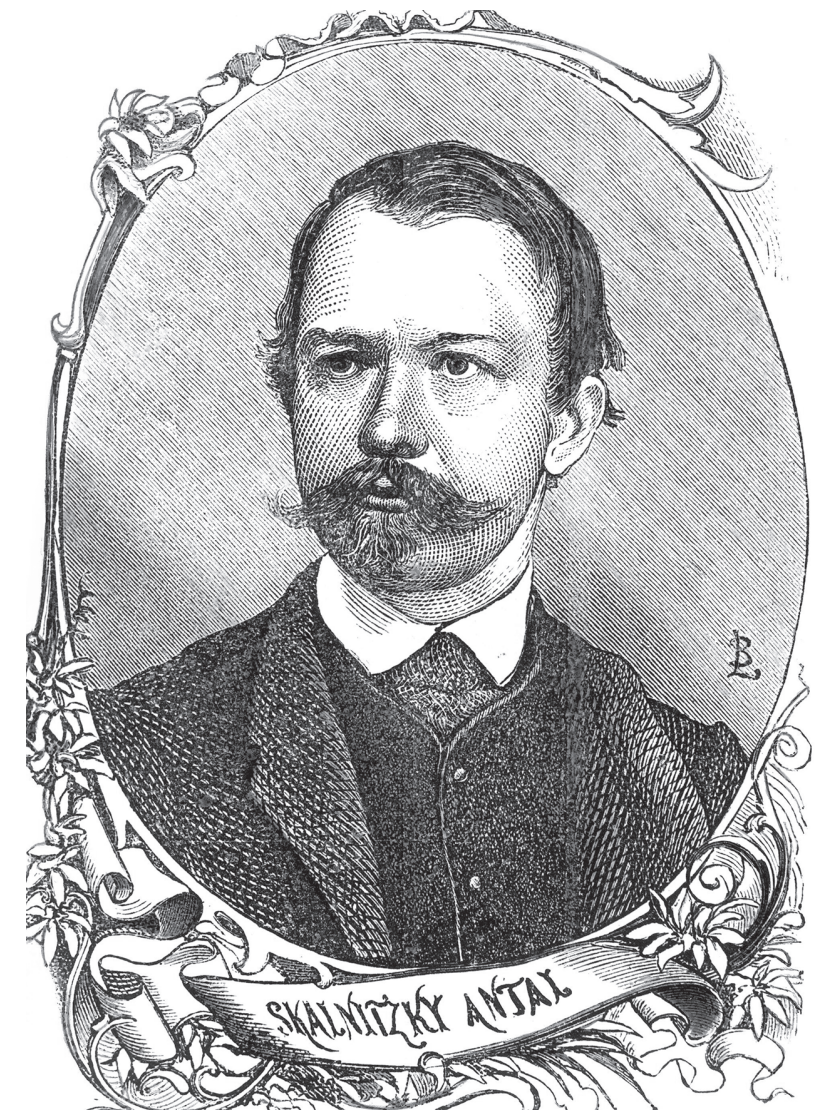

Fig. 1. Antal Szkalnitzky (Emlékkönyv a Magyar Akademia palotájának megnyitási ünnepélyére, [Pest],1865)

les manuels hongrois n'existaient pas, les professeurs devaient compiler leur matériel eux-mêmes. Pour cela, ils s'appuyaient sur leurs propres notes universitaires, sur des collections de patrons reproduits et sur des ouvrages étrangers, surtout allemands. Un jeune instituteur de l'institution, Samu Pecz rédigea en 1886 deux manuels modestes - en réalité plutôt des cahiers - probablement pour l'enseignement. ${ }^{6}$

Toutefois, la bibliothèque de l'Université de technologie, s'enrichissant constamment, était disponible pour aider le travail des professeurs et des étudiants. ${ }^{7}$ L'institution ambitionnait beaucoup son développement, grâce à l'activité débordante de son directeur, Vince Wartha, chimiste et professeur de l'école. La bibliothèque, très modeste à l'origine, possédait une collection de livres grande et variée à la fin du XIX ${ }^{e}$ siècle. Elle se vantait de posséder des livres de patrons, des monographies de bâtiments, de collections d'ornements ainsi que d'ouvrages sur l'histoire et théorie de l'architecture, p.e. par Owen Jones, Eugene-Emanuel Viollet-le-Duc, Gottfried Semper ou Franz Kugler. Parmi les ouvrages classiques conservées à la bibliothèque il faut mentionner un livre francais, celui de 


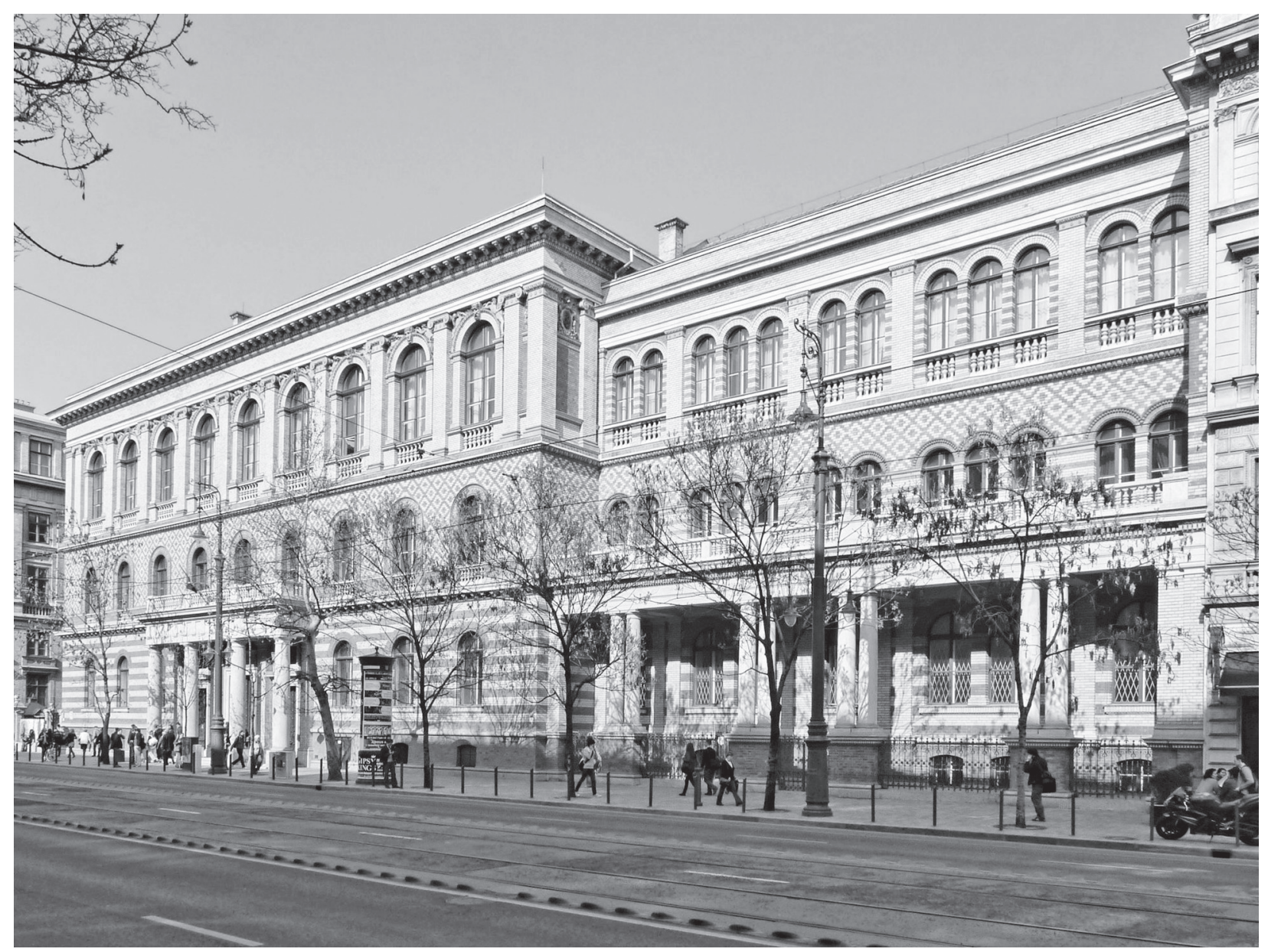

Fig. 2. L’ancienne Université de technologie, Budapest. Imre Steindl, 1880-1882 (Photo József Sisa)

Paul Letarouilly intitulé Édifices de Rome moderne (Paris, 1840-57), dont un exemplaire a été acquis par Antal Szkalnitzky, le premier architecte-professeur de Polytechnique. L'ouvrage de Letarouilly servait presque de Bible pour les architectes, étant une source inestimable pour la connaissance de l'architecture de la Renaissance à une époque où le style néo-Renaissance représentait la tendance la plus populaire. Il faut ajouter que le style néo-Renaissance a joué un róle exceptionnel dans l'architecture budapestoise.

En Hongrie, la recherche dans l'enseignement des architectes est à un stade initial. On peut mentionner avec certitude qu'en outre des livres, ou bien au delà, les patrons reproduits et les moulages en plâtre représentaient des outils d'enseignement beaucoup plus importants. Beaucoup d'entre eux se trouvent actuellement au département du dessin et d'étude des formes de l'Université de technologie. ${ }^{8}$ L'étude et la copie des patrons reproduits faisaient partie de la connaissance de la morphologie. A l'époque de l'historicisme la compréhension des styles du passé comptait parmi les préconditions et formait la base de l'activité créative.
Voyons maintenant quelques moulages en plâtre. Il y a des pièces formant des chapiteaux, qui sont les éléments primordiaux de l'architecture européenne (fig. 5). On peut y découvrir des corniches ainsi que des moulages qui représentent des ornements végétaux (fig. 6). La collection conserve aussi des copies faites de figures humaines ou bien des sculptures. Il y a une maquette en plâtre dont le sort est particulièrement intéressant. Il s'agit de la grande maquette du parlement hongrois qu'Imre Steindl a fait faire de Vilmos Marchenke, le sculpteur décoratif le plus renommé de l'époque ${ }^{9}$ (fig. 7). Comme son échelle mesurait 1:20, sa taille était étonnante: haute de 5 mètres et longue de 15 mètres. A l'aide de la maquette, l'architecte et le comité exécutif pouvaient juger, ou si nécessaire corriger les parties et les détails. Après l'achèvement du bâtiment, la maquette devint inutile. Comme aucune institution ne voulait l'accepter, on l'a démantelée et transférée dans la cave du Parlement. Beaucoup d'années plus tard, en 1907, Alajos Hauszmann a initié le transfert de la maquette, ou de ce qui en resta, à l'Université de technologie, pour des propos d'étude. 


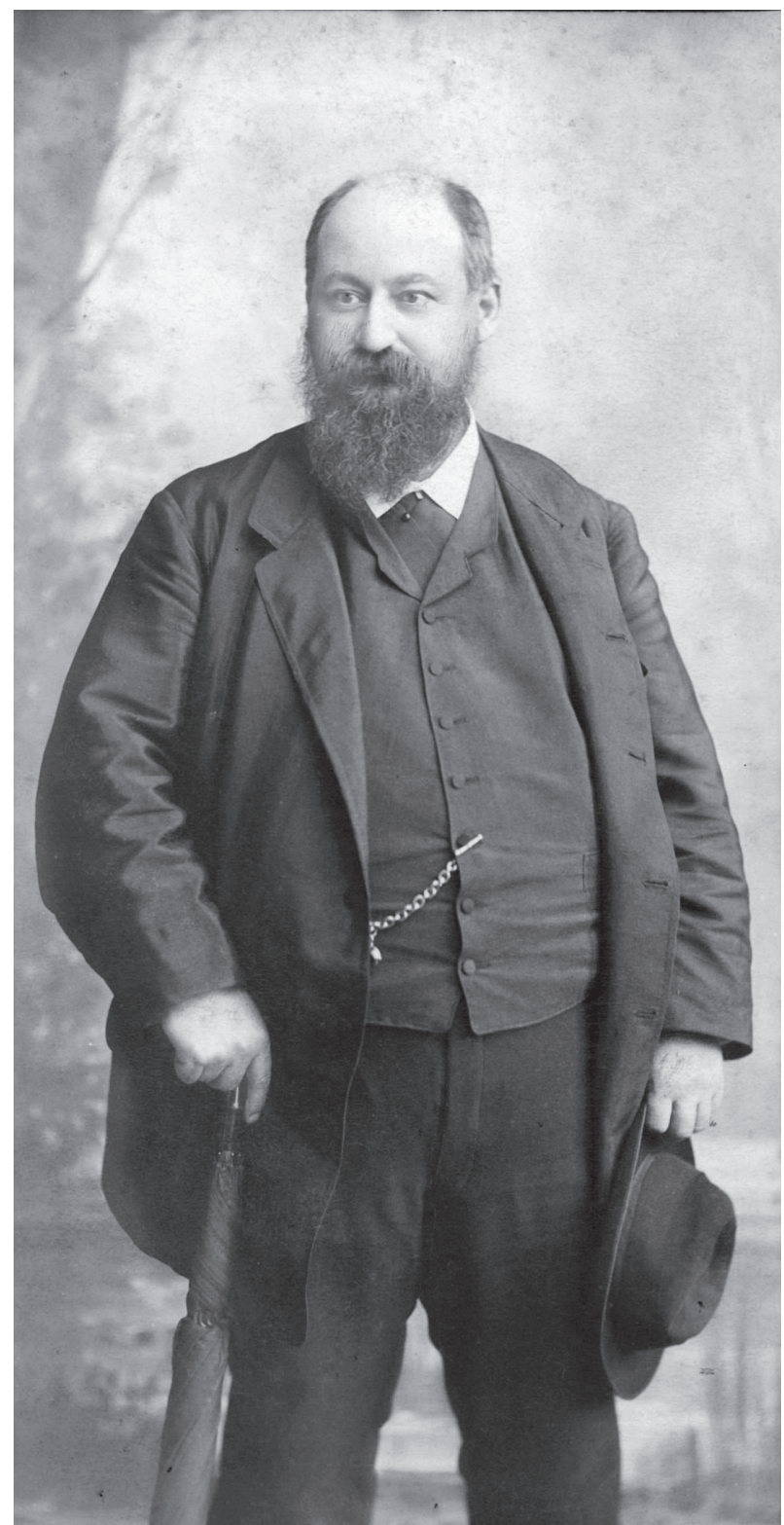

Fig. 3. Imre Steindl. Collection particulière

Malheureusement, ses restes demeurent aujourd'hui introuvables.

Les patrons reproduits utilisés à l'Université de technologie présentent un répertoire des formes comparables à celles des moulages en plâtre. Pour la plupart ils représentent le monde des détails et des ornements de l'architecture. Plusieurs planches proviennent de la collection étant à la disposition des étudiants qui devaient les étudier et les copier (fig. 8). D'autres planches sont les dessins des étudiants mêmes faits d'après des patrons ou des publications (fig. 9). Il y en a parmi eux qui, jugeant de leur technique graphique, sont fait d'après des moulages (fig. 10).

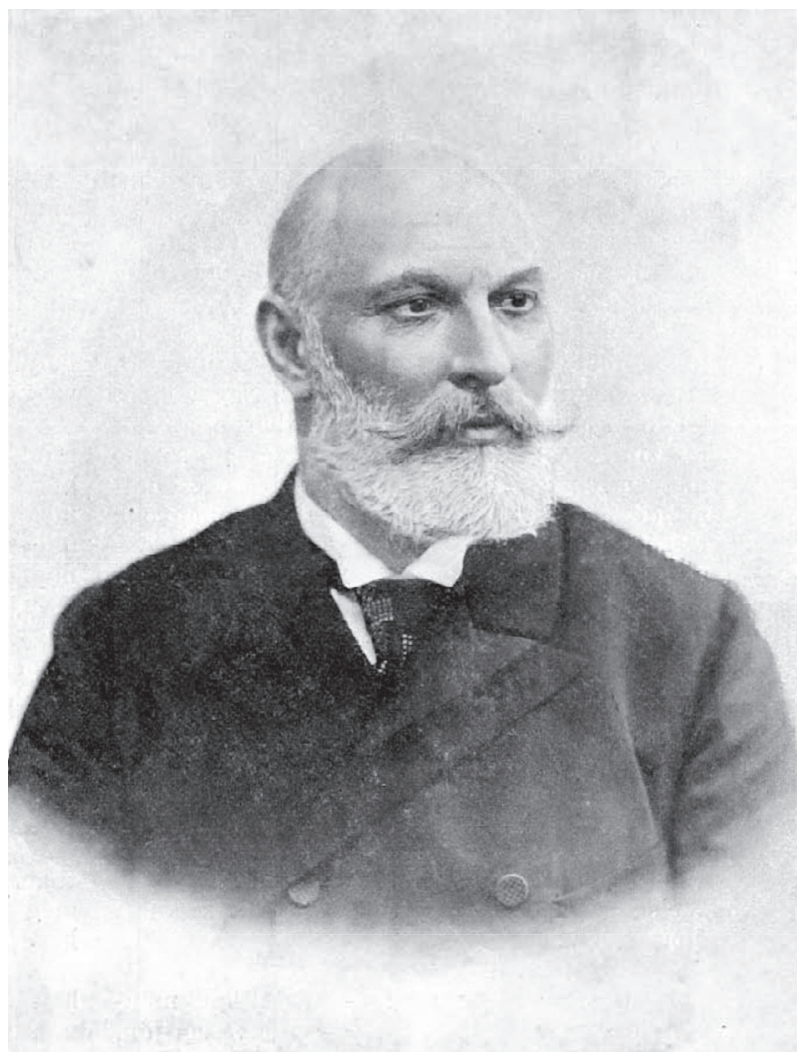

Fig. 4. Alajos Hauszmann

(Vasárnapi Ujság L. 1903. no 36. 585)

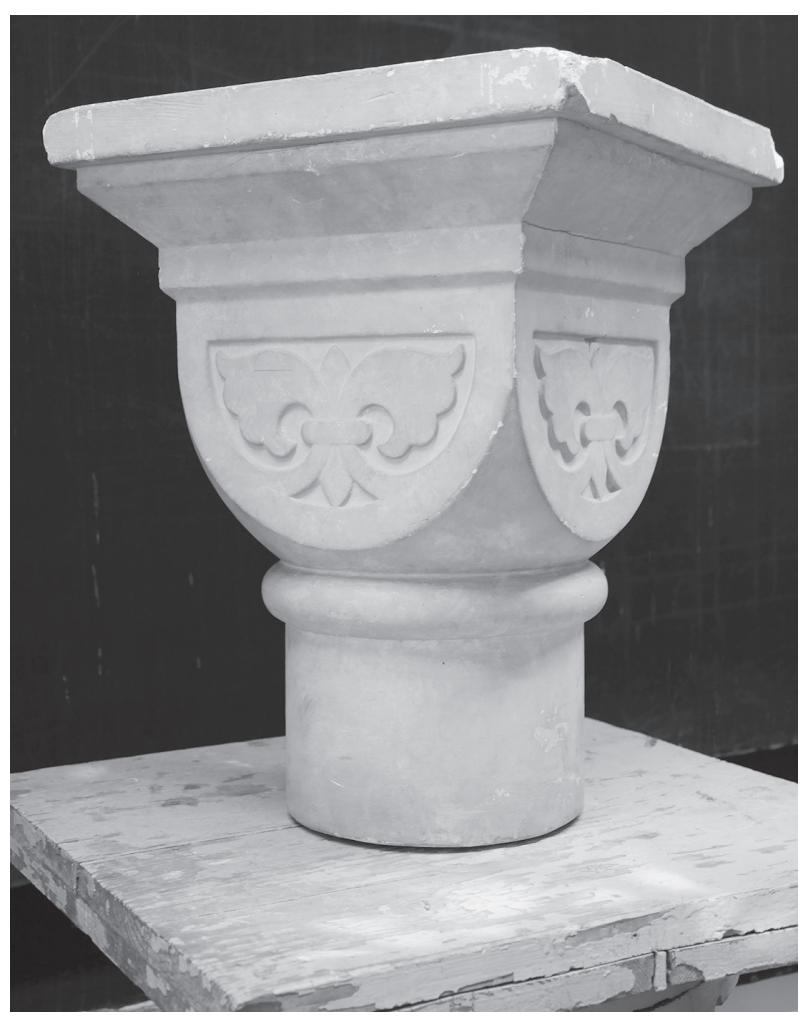

Fig. 5. Chapiteau, moulage en plâtre. Université de technologie, Budapest, collection du département de dessins et de connaissance des formes, 200.142/2 


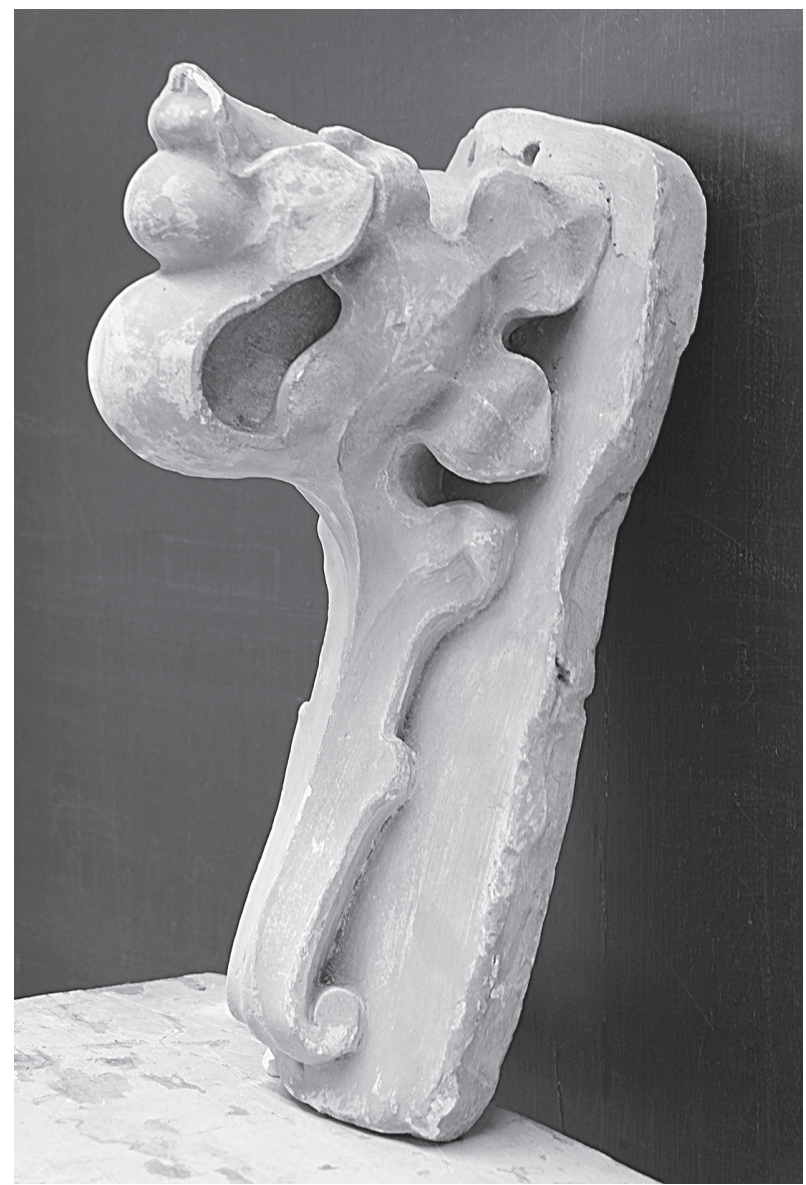

Fig. 6. Ornement, moulage en plâtre. Université de technologie, Budapest, collection du département de dessins et de connaissance des formes, 200.161
On peut se faire une idée de l'étude de l'architecture observant les cours donnés par Frigyes Schulek, le successeur d'Imre Steindl. ${ }^{10}$ En deuxième année, au commencement de leurs études de dessin médiéval, les étudiants ont construit de simples chapiteaux romans, surtout des chapiteaux en cube, d'après l'ouvrage de Gustav Bezold et Georg Dehio, Die kirchliche Baukunst des Abendlandes (L'architecture ecclesiatique de l'Occident, Stuttgart, 1887-1901). Puis ils ont dessiné des arcades, des système de pilastres et des portails. Plus tard, les éléments plus complexes du Gothique apparaissaient; avec le changement du style les tâches devinrent plus difficiles. Pour les formes gothiques le modèle était souvent fourni par les planches de l'association viennoise Wiener Bahütte (fig. 11). Cependant, peu à peu les copies ont été remplacées par la construction indépendante; c'est ainsi que les étudiants sont arrivés de la connaissance des formes historiques à leur application créative.

Hormis l'étude des patrons reproduits et des publications, une autre méthode de la connaissance des vieux bâtiments était l'excursion d'étude, qu'on faisait surtout pendant les vacances d'été. A partir de 1874, Imre Steindl emmena une partie de ses étudiants enthousiastes dans de différentes régions du pays. Au cours du voyage les étudiants eux-mêmes pouvaient faire des dessins, mesurer des monuments historiques, pour la plupart médiévaux. La méthode ressemblait à celle de la Wiener Bauhütte de Vienne. Mais la publi-

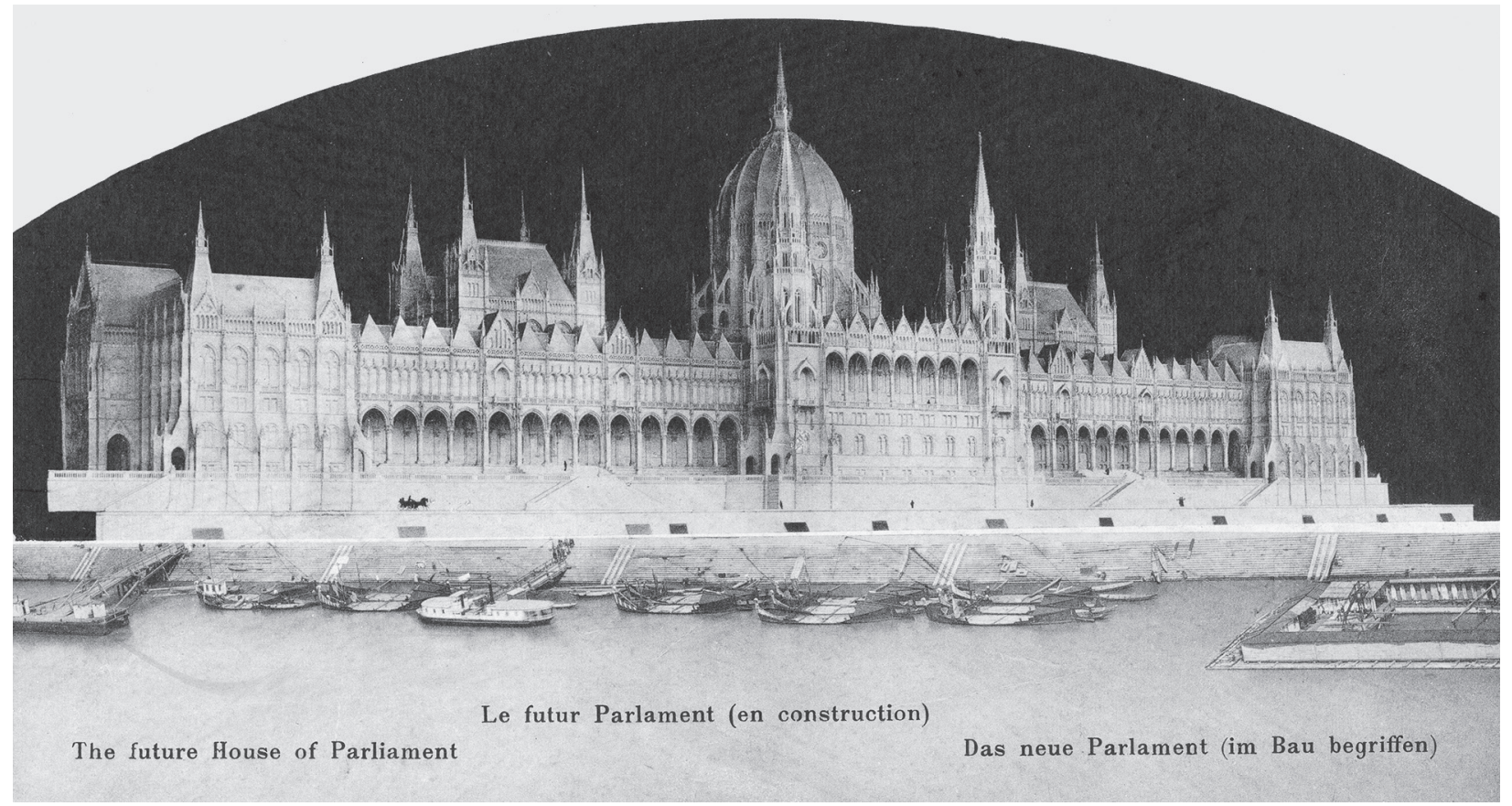

Fig. 7. La maquette en plâtre du parlement hongrois, 1888

(Musée national hongrois, Budapest, photothèque historique, 71-1466) 
cation restait assez modeste: un seul et petit volume est paru Quant aux dessins publiés, on peut constater qu'au delà de la précision technique c'est la réalisation graphique qui domine ${ }^{11}$ (fig. 12).

Quelques dessins des étudiants préparés pour de nouveaux bâtiments sont aussi connus. Un dessin d'étude - essentiellement un dessin idéal - d'Antal

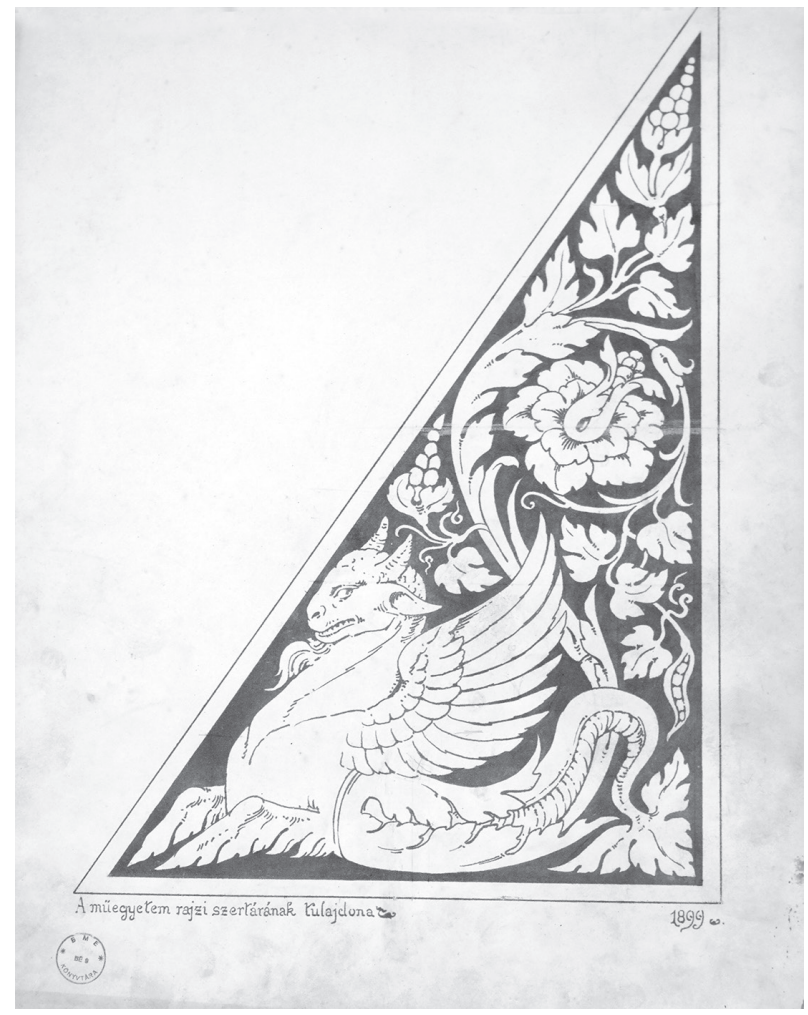

Fig. 8. Patron, 1899. Université de technologie, Budapest, collection du département de dessins et de connaissance des formes, 300.001

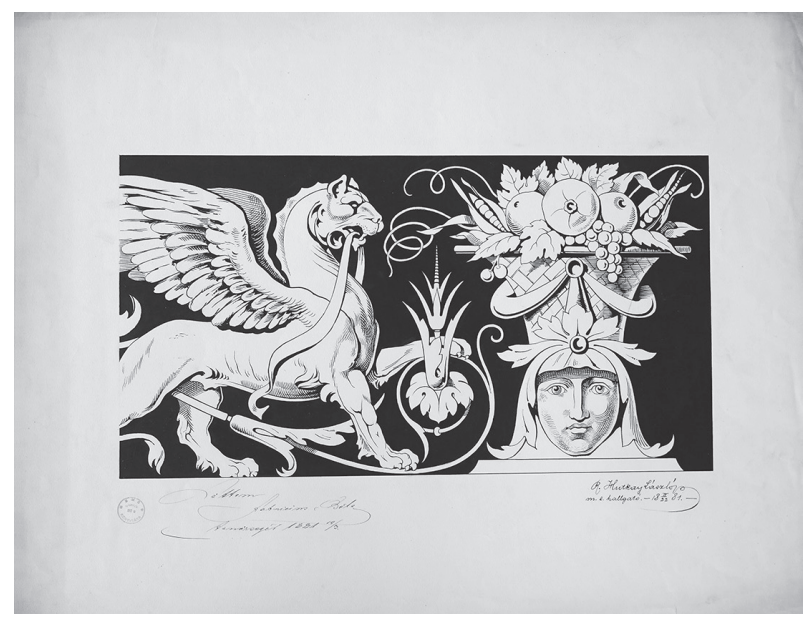

Fig. 9. Dessin de l'étudiant László Hrutkay, 1881.

Université de technologie, Budapest,

collection du département de dessins et de connaissance des formes, 300.003

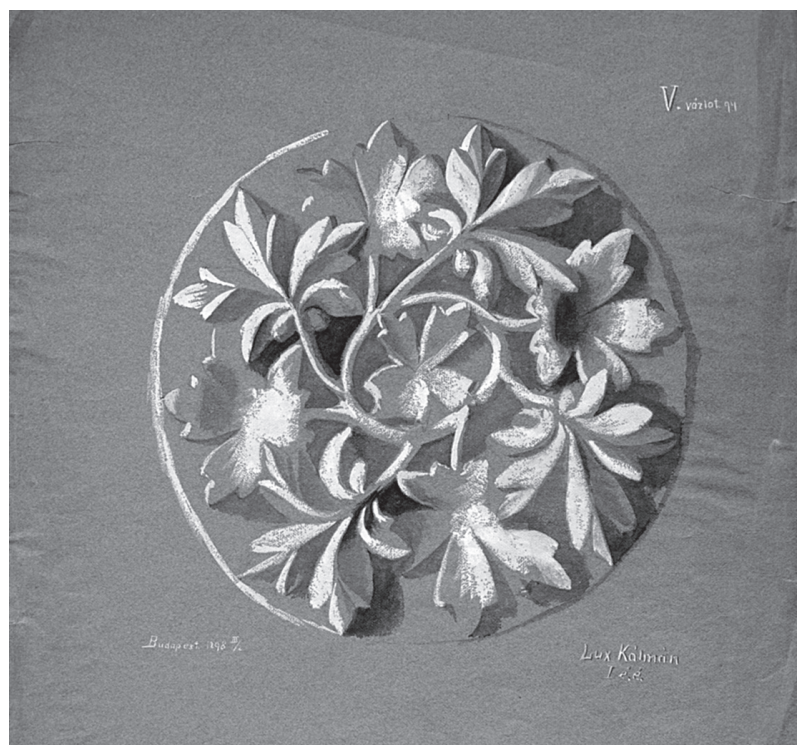

Fig. 10. Dessin de l'étudiant Kálmán Lux d'après un moulage, 1898. Université de technologie, Budapest, collection du département de dessins et de connaissance des formes, 300.002

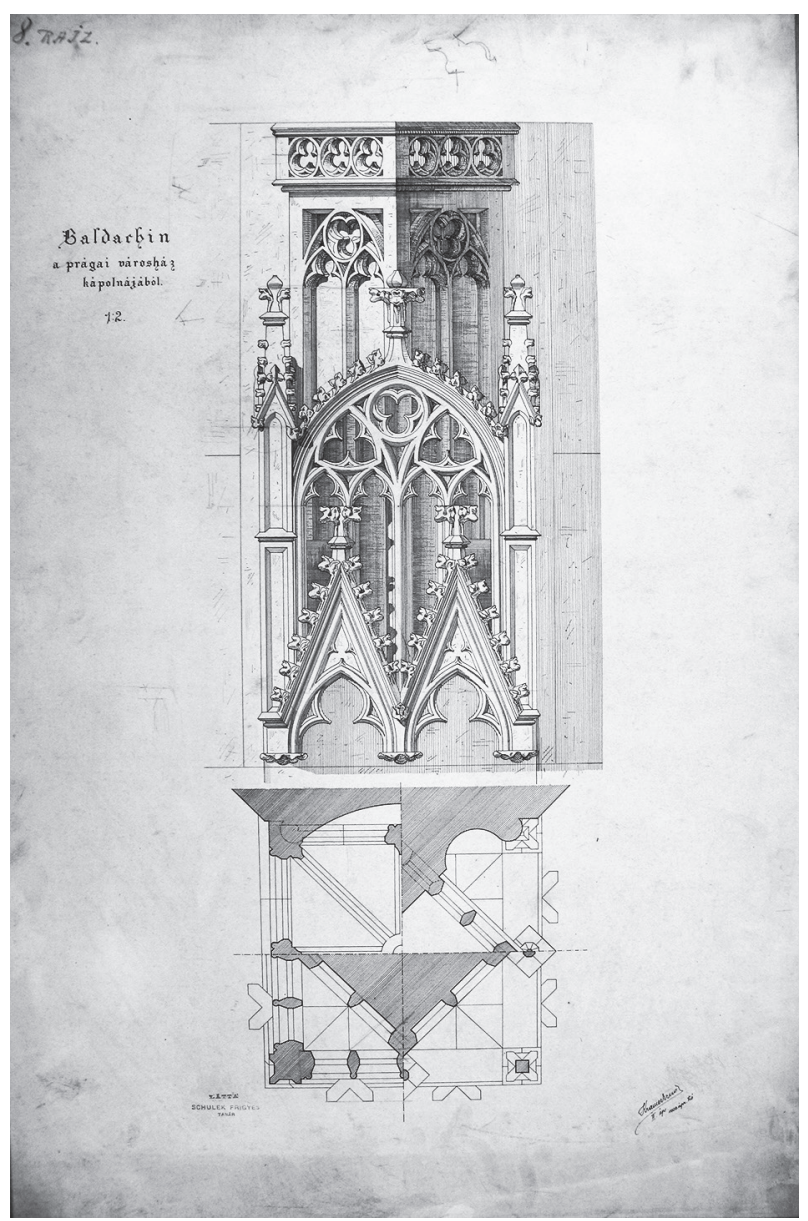

Fig. 11. Dessin de l'étudiant Ernô Krámer d'après la Wiener Bauhütte, 1909. Université de technologie, Budapest, collection du département de l'histoire de l'architecture et des monuments 
Platzer (Palóczi), représentant une redoute pour un jardin ornemental, est conservée (fig. 13). Il date de 1871, de l'époque oú le néo-Renaissance prédominait; évidemment, le dessin de Platzer reflète ce style-là. Au tournant du siècle, quand l'Art Nouveau s'épanouit, la formation d'architectes ne réagit pas de façon positive. Le discours d'inauguration d'Alajos Hauszmann qu'il donne en 1903 comme président de l'Université de technologie est bien connu: il flagelle son ancien ami et camarade d'école, Ödön Lechner pour ses tentatives innovatrices. ${ }^{12}$ Le nouveau bâtiment central de l'Université de technologie construit par Hauszmann en ce temps-là offre une idée comment il s'imagine ce que doit être la juste architecture. Cet édifice et l'entier complexe énorme sont une évidence de l'importance accrue et du pouvoir financier de l'institution.

Les années suivantes - sous l'égide de Frigyes Schulek - la variante monumentale et "éternelle" du style néo-Roman proposa une alternative, indiquant une nouvelle voie pour l'architecture hongroise. De nombreux étudiants de l'Université de technologie travaillent dans ce style, p.e. Béla Jánszky et Lajos Kozma (fig. 14). Sur leurs plans les arches suivent les formes authentiques du Moyen Age, mais la formation des masses et des espaces présagent une attitude nouvelle. Károly Kós, étant lui aussi un étudiant de Frigyes Schulek, prépara son dessin d'étude précoce encore dans le sillage de son professeur. Mait le maître n'empêchait pas les aspirations novatrices de ses élèves. L'exposition de dessins des étudiants de l'architecture en 1906 s'avéra être un grand succès, elle suscita un vif intérêt auprès du grand public. Les étudiants en question fonderont bientốt leur groupe nommé „Fiatalok”, qui signifie „Les jeunes” en francais, et qui jouera un grand rôle dans le sort de l'architecture hongroise.

L'enseignement de l'art, ci-inclus l'art décoratif, appartenait au programme de la modernisation de la Hongrie comme aussi celui de l'architecture. Les deux procédaient de pair souvent avec des contacts professionnels. On peut se rendre compte du début de ces effort dès que le baron József Eötvös, ministre de la culture envoya le peintre et critique de l'art Gusztáv Keleti en 1868 à un voyage d'étude à l'étranger. Au cours de son voyage Keleti visita systématiquement les institutions de la formation artistique en France, en Angleterre, en Belgique, en Allemagne et en Autriche afin de rédiger une proposition pour l'établissement de la structure institutionnelle de l'enseignement de l'art au niveau supérieur. Il l'a fait dans son livre A képzômúvészeti oktatás külföldön és feladatai

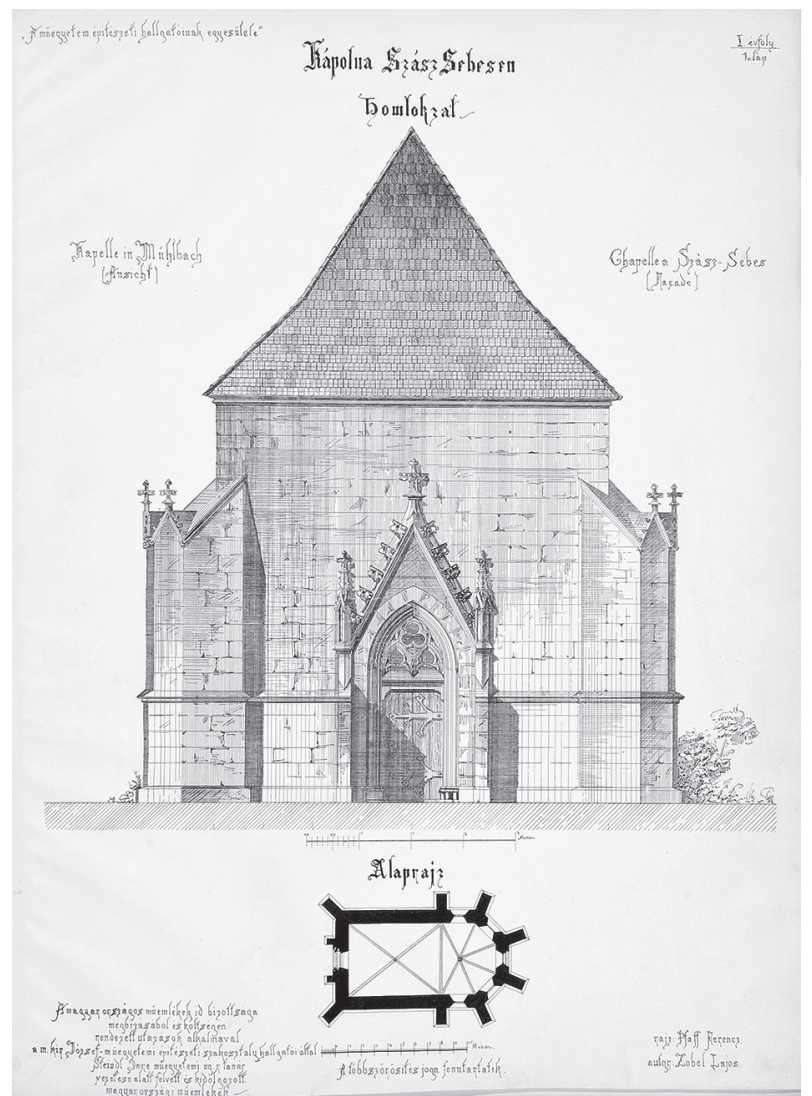

Fig. 12. La façade de la chapelle à Szászsebes (Mühlbach, Sebeș, Roumanie), relevé des étudiants Ferenc Pfaff et Lajos Zobel (Magyarországi múemlékek, Budapest, 1878)

hazánkban (La formation artistique à l'étranger et ses devoirs dans notre pays, Budapest, 1870).

L'année suivante, sous le directorat de Gusztáv Keleti on ouvrit l'École normale royale hongroise de dessin et séminaire de professeurs de dessin (Magyar Királyi Országos Mintarajziskola és Rajztanár képezde) - plus brièvement: l'École normale de dessin (Mintarajziskola) -, l'établissement d'origine de la formation artistique hongroise. ${ }^{13}$ L'enseignement comporte trois facultés: celle de peinture, de sculpture et de l'ornement architectural. Ce dernier sujet a été enseigné par Frigyes Schulek, un personnage marquant de l'École normale de dessin, qui en 1903, après la mort d'Imre Steindl, poursuivra sa carrière à l'Université de technologie. Il n'était pas le seul qui enseigna d'abord à l'École normale de dessin puis à l'Université de technologie ou inversement. A cet égard il y avait un échange actif entre les deux institutions. Le bâtiment de l'École normale de dessin fut érigé dans la rue la plus élégante de Budapest, l'avenue Andrássy (fig. 15). L'un de ses auteurs était Lajos Rauscher, l'instigateur et professeur de l'ornementation de l'école. Le bâtiment avec son éclatante façade, sa peinture décorative se devait d'afficher sa fonction 
élevée. Au sein de l'École normale de dessin on a ouvert en 1880 l'Institut d'enseignement national hongrois royal de l'art décoratif (Országos Magyar Királyi Iparmúvészeti Tanoda) - ou plus brièvement: l'Institut d'enseignement de l'art décoratif - qui deviendra plus tard une institution indépendante de grande importance. ${ }^{14}$

Les débuts se sont avérés assez modestes: elle possédait un seul chantier pour „sculpter le bois”, un seul professeur, et en première année comptait seulement sept étudiants. Les étudiants travaillaient tout d'abord sur le chantier, de plus ils apprenaient le dessin architectural et l'art décoratif, et comme matières auxiliaires la géométrie, la perspective à main libre et et le dessin d'ornement. Au cours des années suivantes les objets se sont multipliés, on a commencé à enseigner l'orfèvrerie, la gravure sur bois, la peinture d'ornement, la gravure à l'eau-forte et la sculpture d'ornement. A partir de 1890, des cours du soir furent organisés pour la formation supplémentaire des apprentis.

La bibliothèque de l'École normale de dessin était riche, elle possédait une belle collection d'ouvrages professionnels allemands, francais et anglais du XIX siècle. ${ }^{15}$ Elle comprenait de nombreux tomes consa- crés aux villes ou aux bâtiments uniques, ci-inclus des albums avec des illustrations en gravure ou en photographie. Les ouvrages traitant la morphologie architecturale ou l'ornementation formaient un groupe à part. Surtout ces derniers sont importants. Il y a quelques années, on a publié un livre sur cette collection de raretés se composant de presque 500 pièces, unique en Hongrie. ${ }^{16}$ Il est utile de citer quelques ouvrages français parmi les suivants: Peintures murales des chapelles de Notre-Dame de Paris par Eugene-Emanuel Viollet-le-Duc (Paris, 1876), Les arts arabes par Jules Bourgoin (Paris, 1873), ou Histoire de l'art Égyptien par Prisse d'Avennes (Paris, 1878-79). Mais il existaient déjà des ouvrages hongrois : le livre de Károly Pulszky et Friedrich Fischbach A magyar házi ipar díszítményei (Ornements de l'industrie a domicile hongroise, Budapest, 1878), qui était en Hongrie un pionnier dans son domaine, ou Magyar diszítmények (Ornements hongrois, Budapest, 1910) par Szilárd Várdai, qui reflétait un intérêt pour l'art folklorique (fig. 16).

En 1896, l'Institut d'enseignement de l'art décoratif est devenu indépendant de l'École normale de dessin, et il a déménagé dans un nouveau bâtiment abritant aussi

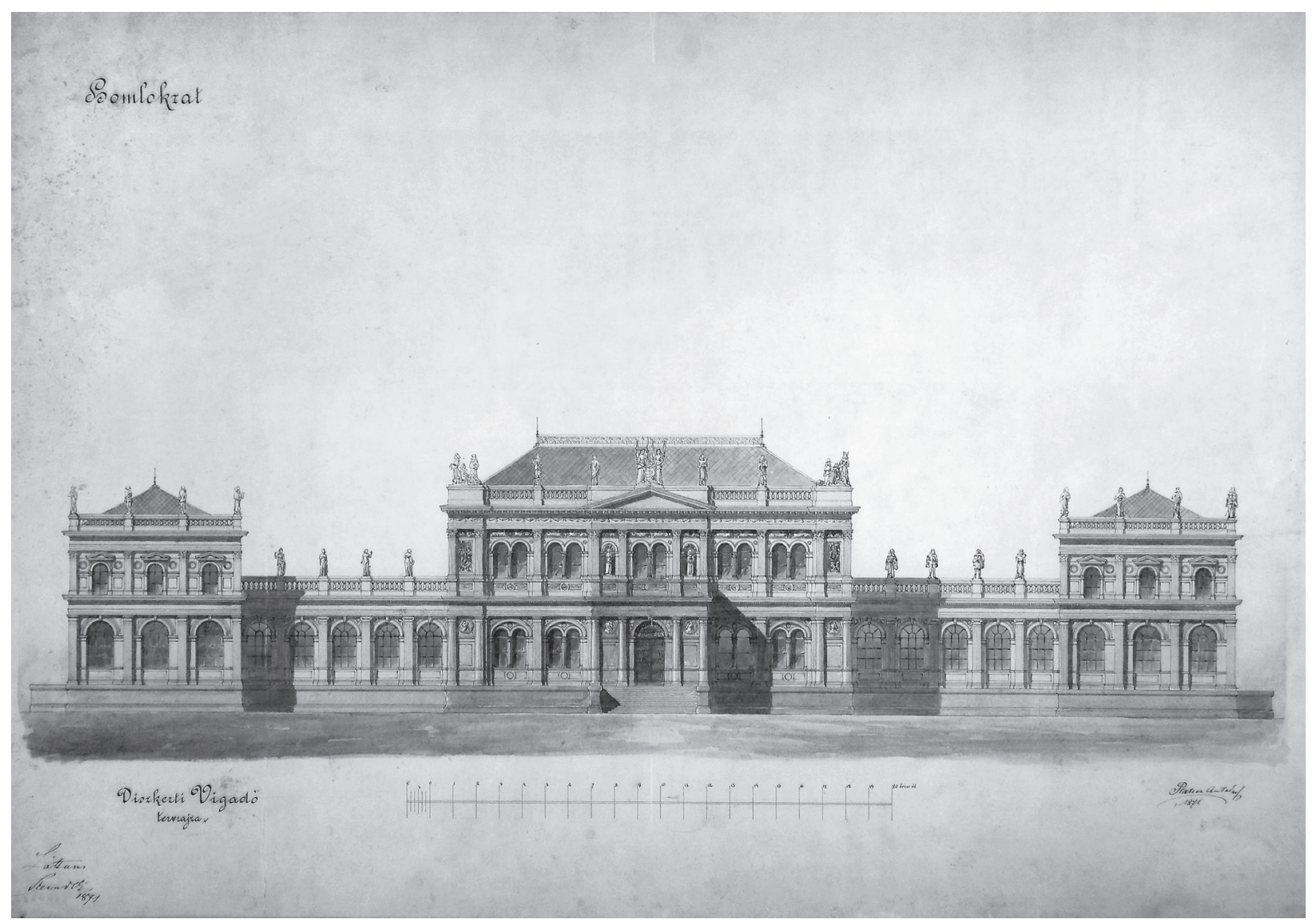

Fig. 13. Dessin d'étude (redoute) de l'élève Antal Platzer à l'Université de technlologie, 1871. Musée hongrois de l'architecture, Budapest 


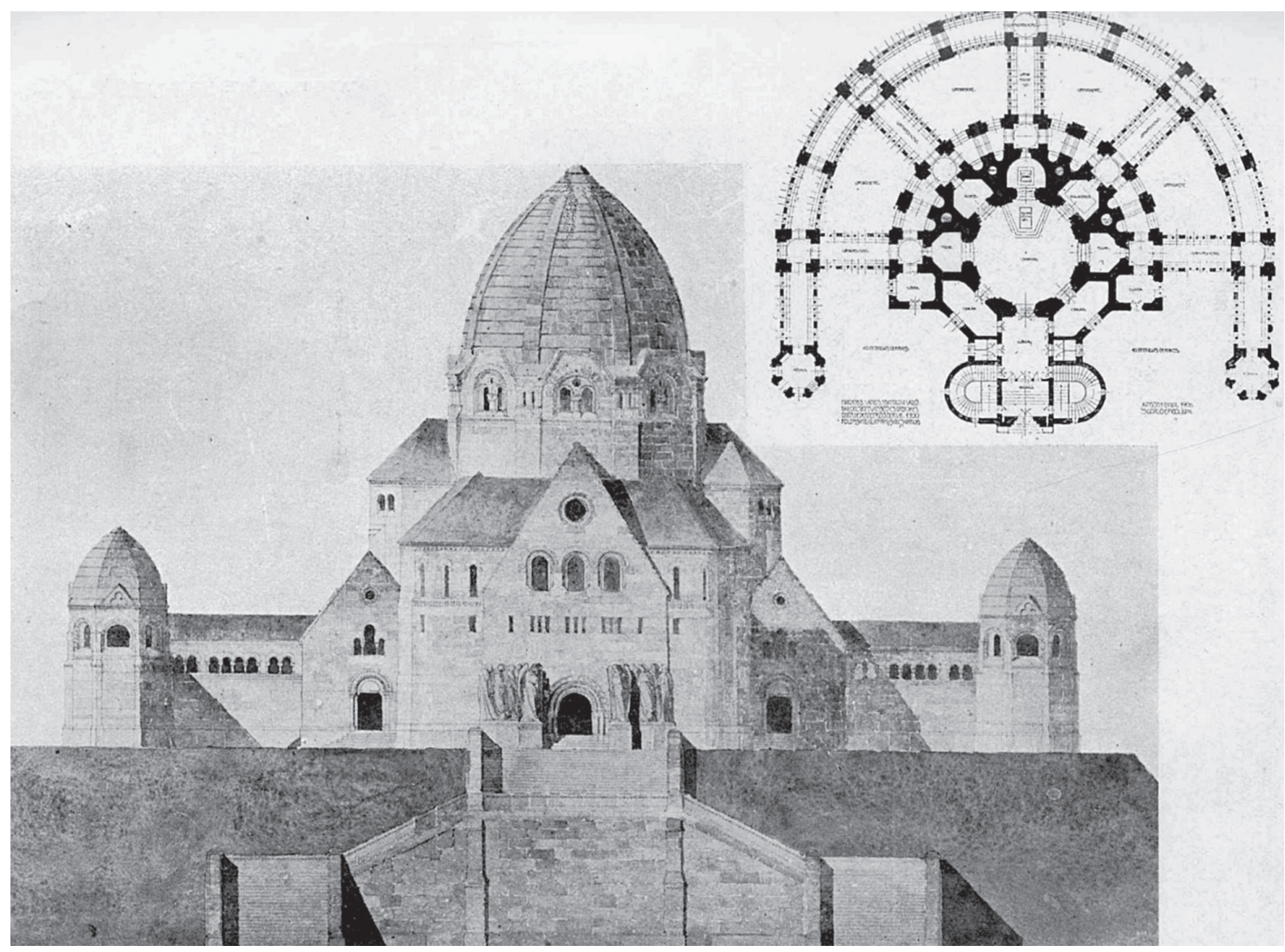

Fig. 14. Dessin d'étude (crematorium) de l'élève Béla Jánszky, 1907. (Magyar Pályázatok V. 1907. n 1. 17)

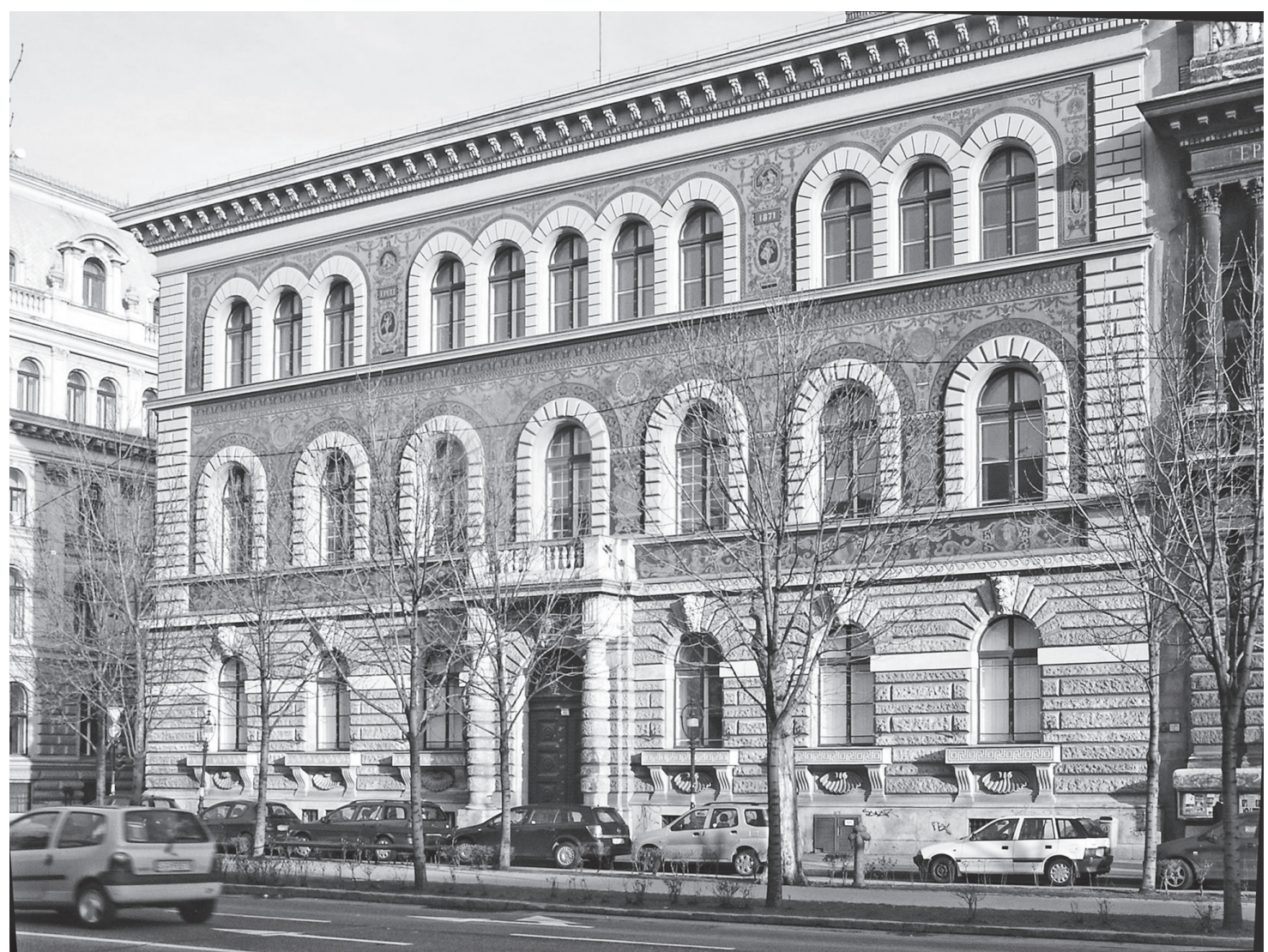

Fig. 15. L'école normale de déssin, Budapest. Lajos Rauscher - Ferenc Kolbenheyer, 1875-1876 (Photo József Sisa) 


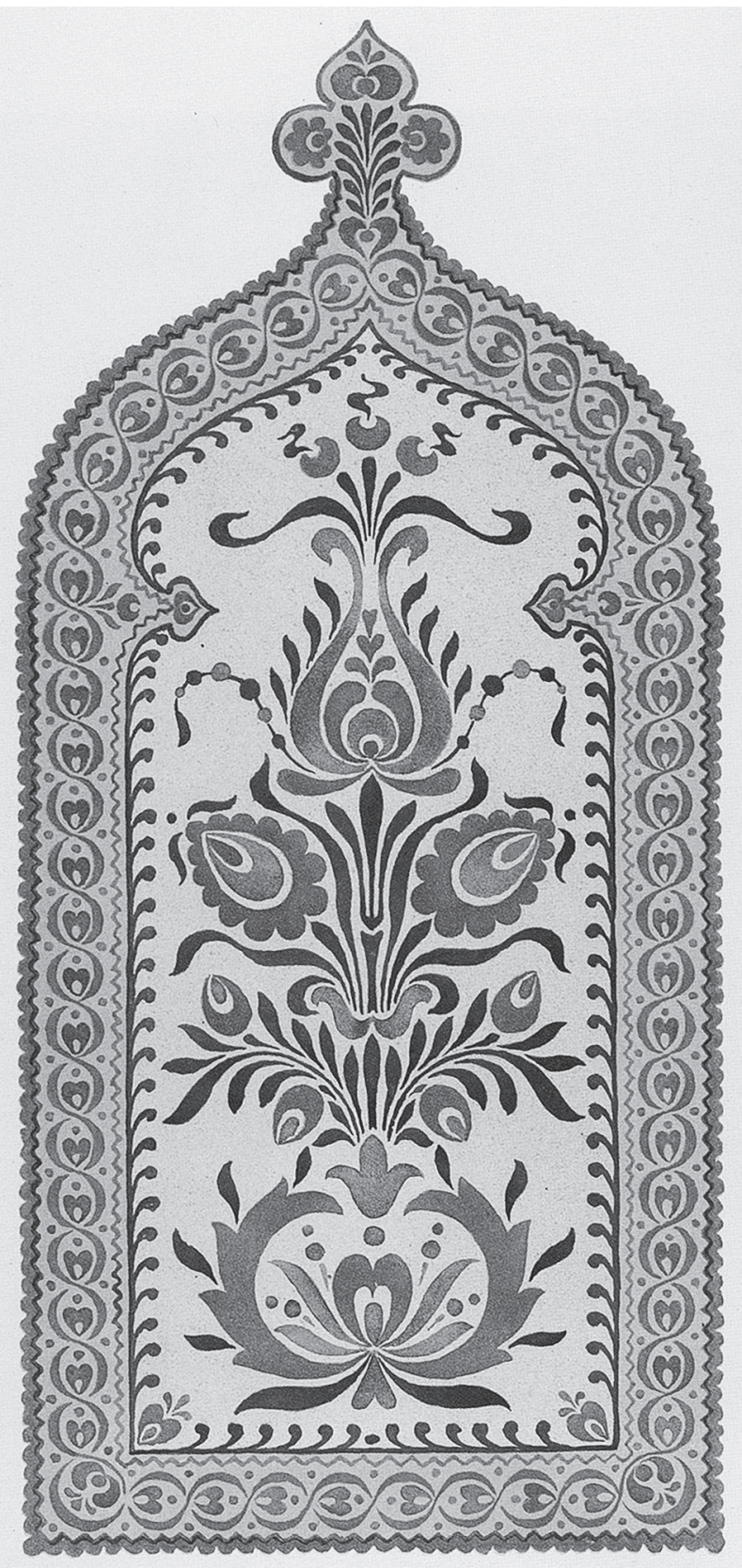

Fig. 16. Ornement hongrois

(VÁRDAI, Szilárd: Magyar díszítmények, Budapest, 1910)

le Musée de l'art décoratif. L'édifice, dont les auteurs sont Ödön Lechner et Gyula Pártos, représente une oeuvre unique et révolutionnaire dans l'architecture hongroise, et aujourd'hui jouit d'un renommée internationale. Sa façade, couverte de céramique, devait afficher déjà avec son apparence l'idée de l'art décoratif. La collection du musée faisait office de dépốt d'exemples pour l'enseignement. A l'époque, on considérait la coopération du musée et de l'école comme une solution idéale dans la formation artistique. Nous sommes encore dans la période de l'historicisme - bien qu'à sa fin -, où les modèles historiques jouent un róle éminent. Le premier directeur de l'Institut d'enseignement de l'art décoratif était Kamill Fittler, architecte et auteur d'ouvrages professionnels. En ce temps-là, 120 étudiants inscrits fréquentaient déjà l'institution (fig. 17-18). En 1899 un nouvelle classe, celle de la décoration intérieure a commencé. Au tournant du siècle le mouvement anglais Arts and Crafts a exercé une grande influence sur l'activité de l'école, dont l'adaptation a exprimé le désir de la culture hongroise de se détacher de Vienne et de l'Allemagne. La recherche de l'art populaire et la publication de ses motifs représentaient une autre direction pour le renouveau de l'art décoratif hongrois.

L'Institut d'enseignement de l'art décoratif possédait une collection de moulages en plâtre, qui fut malheureusement détruite. Toutefois il est connu que même dans la première décennie du $\mathrm{XX}^{\mathrm{e}}$ siècle il existait la pratique du dessin et du modelage d'après moulages (fig. 19). Dans les cours préparatoires de la classe de sculpture ornementale, les élèves modelaient ou taillaient de cette façon les ornements d'abord simples, puis graduellement plus compliqués.

Conjointement à la formation des artistes, l'enseignement des artisans et l'établissement des institutions pour ce propos se déroulaient avec le même élan. A la suite de la loi de l'industrie adoptée en 1872, un grand nombre d'écoles industrielles se sont ouvertes. On trouve parmi elles des institutions d'enseignement de charpentiers, de maçons, de ferblantiers, de serruriers, de mécaniciens, de potiers, etc.

Le centre de l'enseignement de dessin pour les apprentis se trouvait à l'Ecole municipale de dessin industriel de Budapest (Budapest Székesfóvárosi Iparrajziskola), fondée en 1886. L'enseignement du dessin avait en Hongrie une tradition de longue date: on a lancé l'école à Buda en 1778, puis à Pest en 1788, leur successeur légal étant l'institution en question. A coté de l'enseignement des métiers on y donna des cours publics de dessin. L'essence des réformes introduites en 1904 se constituait d'un enseignement sur le chantier au cours duquel on mettait l'accent sur la maîtrise des matériaux et des techniques industrielles. Cette dernière évolua vers l'art décoratif, afin que l'artisan "représente dans une personne l'auteur et le réalisateur". Grâces aux réformes, l'école pouvait assurer aux élèves un enseignement total, pratique ainsi que théorique. La collection de l'institution a survécu tous les tourments historiques et est conservée aujourd'hui de façon exemplaire.

Il est intéressant de noter que la muséologie de l'époque soutenait également le développement de l'industrie. Le Musée d'industrie technologique représen- 


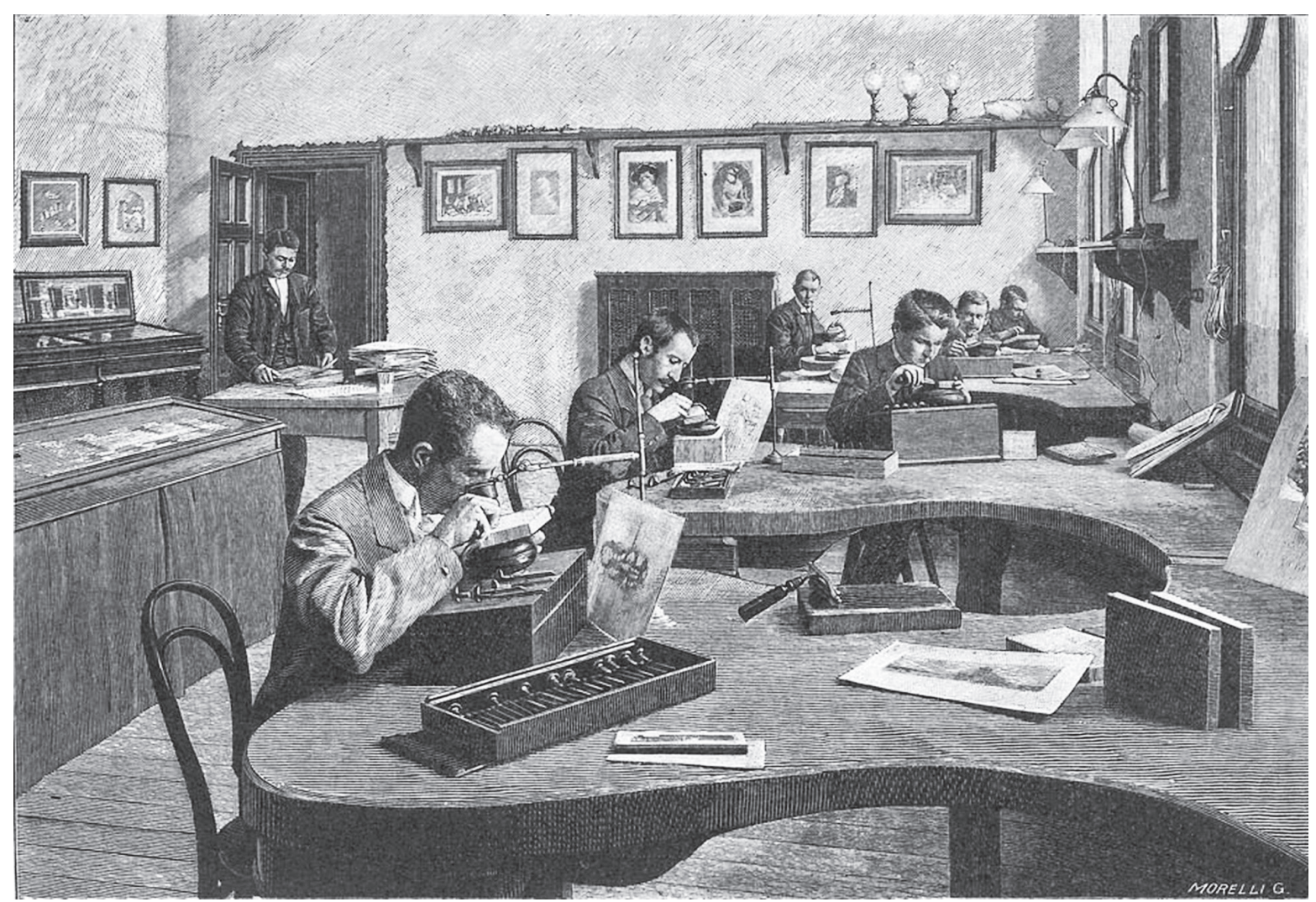

Fig. 17. Classe de gravure sur bois à l'École des arts décoratifs (Magyar Iparmũvészet I. 1898. n 9. 401)

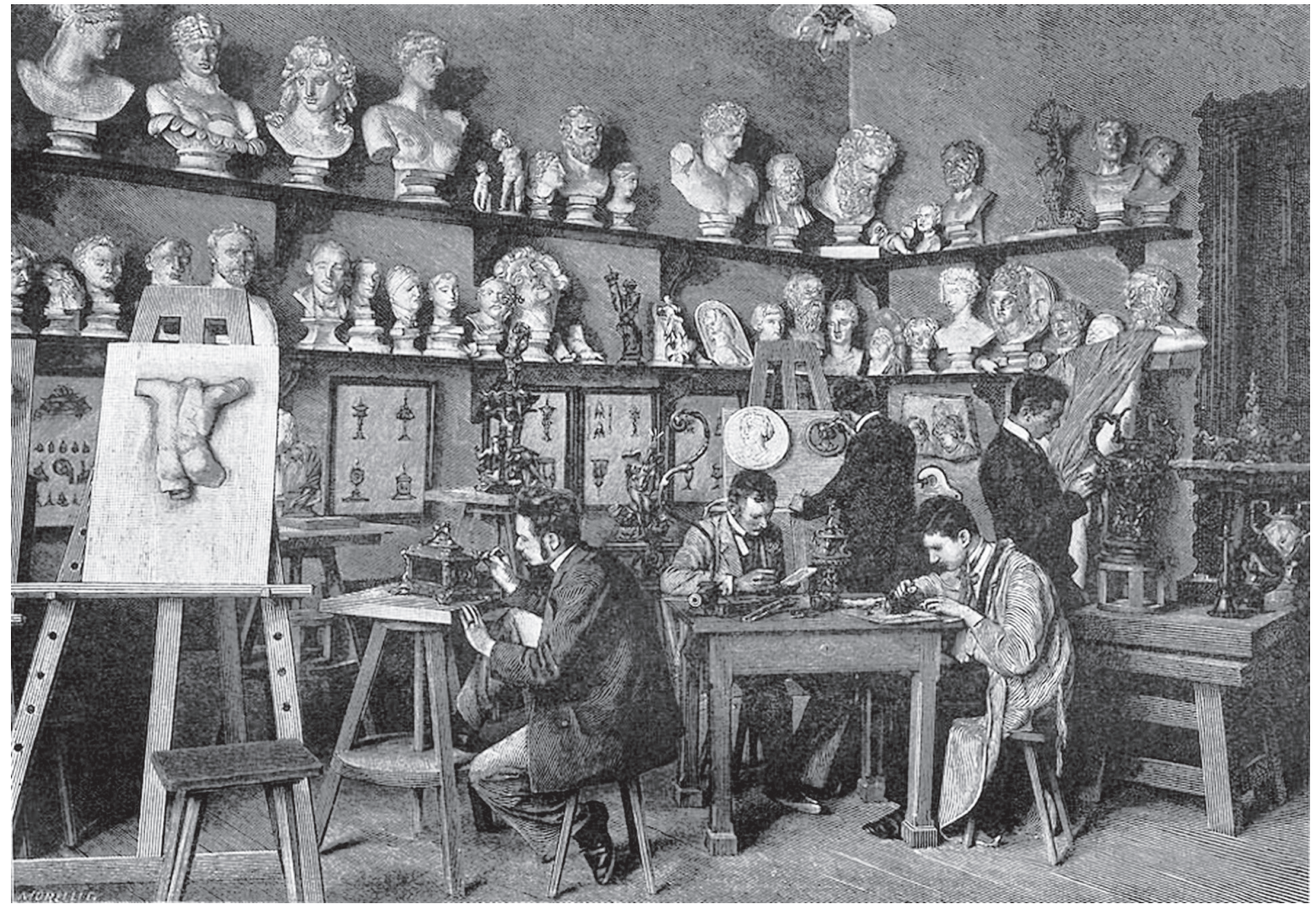

Fig. 18. Classe d'art plastique à l'École des arts décoratifs (Magyar Iparmúvészet I. 1898. n 9. 401) 


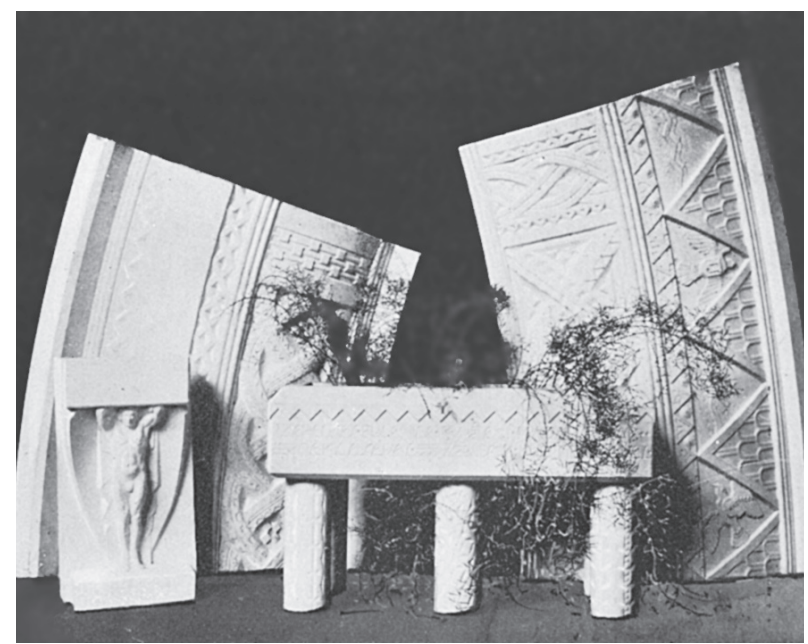

Fig. 19. Moulages d'étude à l'École des arts décoratifs (Az Országos Magyar Királyi Iparmúvészeti Iskola Értesítóje, Budapest, 1908) tait la plus importante institution de ce type (fig. 20). Son bâtiment, dont l'auteur était Alajos Hauszmann et qui se trouve sur le grand boulevard de Budapest, abritait aussi l'École supérieure de l'industrie (Felsôipariskola) telle sorte qu'à nouveau un musée et une école existaient en symbiose. ${ }^{17}$ En réalité, dans ce cas on ne peut utiliser l'expression „musée” qu'avec réserve étant donné que l'institution possédait pour la plupart des machines modernes. Dans l'esprit du programme national, deux autres musée d'industrie ont été érigés à l'est du pays, a Kolozsvár et a Marosvásárhely. ${ }^{18}$

En somme on peut constater que dans les décennies qui suivirent le compromis austro-hongrois, le système de l'enseignement et de l'apprentissage dans le domaine de l'architecture et de l'art décoratif fut établi avec succès en Hongrie. A cet égard, le pays est devenu un état européen moderne.

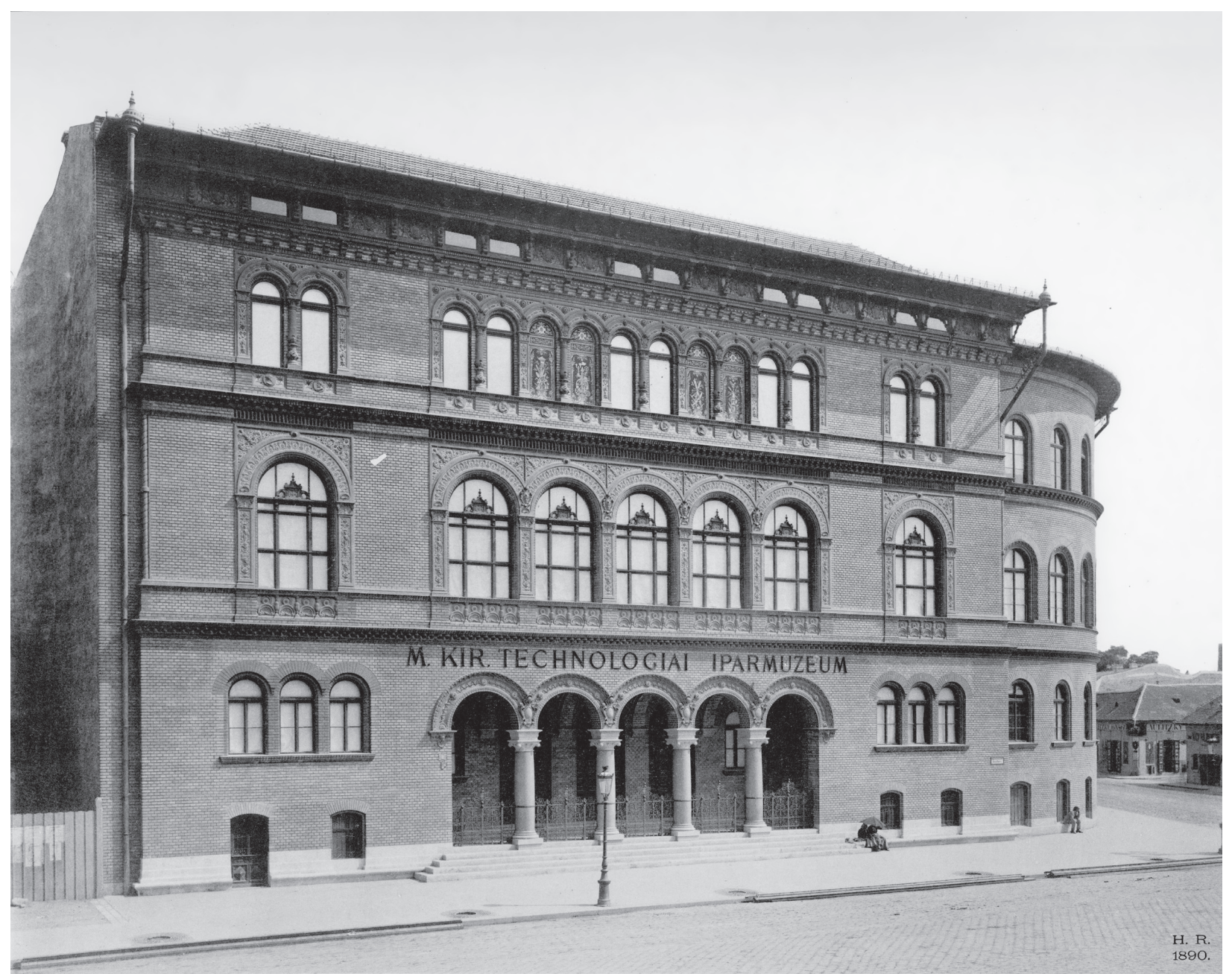

Fig. 20. Le Musée d'industrie technologique et l'École supérieure de l’industrie, Budapest. Alajos Hauszmann, 1887-1889 (RÜCKWARDT, Hermann: Architektonische Studienblätter aus Budapest, Berlin, 1890) 


\section{NOTES}

${ }^{1}$ Le texte de cet article est identique avec la conférence de l'auteur donnée au colloque „Budapest, la naissance d'une métropole”, organisé par l'Institut hongrois à Paris le 16 mai 2017.

2 KOMÁRIK, Dénes: Építészképzés és mesterfelvétel a XIX. században. Pesti mesterek és mesterjelöltek, Építés-Épitészettudomány III. 1971. no 4. 379-418. - Sur l'architecture, l'art décoratif et l'enseignement en Hongrie au XIX ${ }^{\mathrm{e}}$ siècle en général, voir SISA, József (Ed.): Motherland and Progress: Hungarian Architecture and Design 1800-1900, Bâle, 2016.

3 Balogh, István: Beregszászi Pál és a debreceni „Rajzoskola” 1819-56, Mũvészettörténeti Értesítô IX. 1960. nº 1. 44-45; SzABOlCSI, Hedvig: Magyarországi bútormũvészet a 18-19. század fordulójân, Budapest, 1972; Kopasz, Gábor: Buck József és a pécsi rajziskola elsô évtizede, in ZÁDor, Anna - Szabolcsi, Hedvig (red.): Mũvészet és felvilágosodás. Múvészettörténeti tanulmányok, Budapest, 1978, 343-391.

${ }^{4}$ SzEnTKIRÁlYI, Zoltán: Adatok a magyar építészképzés történetéhez, Épités-Építészettudomány III. 1971. no 4. 349-465.

${ }^{5} \mathrm{Az}$ építészeti oktatás a Múegyetemen, Mũvészeti Ipar I. 1885/1886. 29.

${ }^{6}$ PECZ, Samu: A görög kôszerkezetek ismertetése, különös tekintettel a görög-dór szentélyekre, Budapest, 1886; PECZ, Samu: Az ó-keresztény templom-építészet fejlödése, Budapest, 1886.

${ }^{7}$ A m. kir. József-múegyetem könyvtárának czímjegyzéke, $2^{\mathrm{e}}$ édition, Budapest, 1893.

${ }^{8}$ Pour leur connaissance et leur photos je voudrais exprimer mes reconnaissances à Me. Júlia Katona et M. Ferenc Sebestyén.

9 SisA, József: „Fôszminták” az Országházhoz - tervezési segédlet és látványosság, Ars Hungarica XLII. 2016. nº 3. 213-222.
10 Salamon, Gáspár: „Aztán vigyázzon, el ne csússzék ..". Elmélet, gyakorlat és fontolva haladás a múegyetemi Schulek-tanszéken, Ars Hungarica XL. 2014. no 3. 338-350.

${ }^{11}$ Magyarországi múemlékek. Kiadja a Múemlékek Országos Bizottságának hozzájárulásával a Budapesti M. K. József Mủegyetem építészi hallgatóinak egyesülete Steindl Imre, ny. r. tanár vezetése alatt, Budapest, 1878.

12 Hauszmann, Alajos: Rektori beszéd, József Múegyetem, 1903. szeptember 16., Budapest, 1904.

${ }^{13}$ BLaskóné MajKó, Katalin - SzÕKe, Annamária (red.): A Mintarajztanodától a Képzômúvészeti Fôiskoláig, Budapest, 2002.

${ }^{14}$ Mezei, Ottó: Az Orsz. M. Kir. Iparmûvészeti Iskola (1880-1944) oktatási rendszere és forrásai, Mưvészettörténeti Értesítő XXIV. 1975. no 1. 37-55.

${ }^{15}$ Az Országos Magyar Királyi Mintarajziskola és Rajztanárképzô könyvtárának czímjegyzéke, Comp. VÁRDAI, Szilárd, Budapest, 1900.

${ }^{16}$ Katona, Júlia - GYÖRGY, Judit: Díszítmények és ideák vonzásában. A Magyar Képzômüvészeti Egyetem díszítômüvészeti könyvritkaság gyûjteménye, Budapest, 2010.

${ }^{17}$ A magyar királyi Technológiai Iparmúzeum és a budapesti m. kir. állami Ipariskola egyesített szakkönyvtárának czímjegyzéke, Comp. Grünwald, István, Budapest, 1898; Jesch, László (red.): A budapesti magy. kir. Állami Felsôipariskola emlékkönyve az intézet 60 éves fennállása alkalmából, Budapest, 1939.

18 SzÉKELY, Miklós: A magyarországi ipari szakoktatási rendszer a századfordulón, különös tekintettel Erdélyre, in Táguló horizont: Tanulmányok a fiatal müvészettörténészek marosvásárhelyi konferenciájânak elôadásaiból, Marosvásárhely Kolozsvár, 2013, 129-141; SzÉKELY, Miklós: Nemzet, ipar, múvészet. A kolozsvári I. Ferenc József Iparmúzeum 18871919, Budapest, 2017 